\title{
Nanoadsorbent of Organic Compounds Based on Two- and Three- Dimensional Mesocylinder Monoliths
}

\author{
Sherif A. EL-Safty ${ }^{1,2 *}$, M. Khairy ${ }^{1}$ and M. Ismael $^{1}$
}

${ }^{1}$ National Institute for Materials Science (NIMS), 1-2-1 Sengen, Tsukuba-shi, Ibaraki-ken, 305-0047, Japan

${ }^{2}$ Graduate School for Advanced Science and Engineering, Waseda University, 3-4-1 Okubo, Shinjuku-ku, Tokyo, 169-8555, Japan

\begin{abstract}
The considerable contamination of the aqueous environment by organic pollutants still requires the development of effective adsorbents for removal of these compounds. The current work reports the applicability of hexagonal and cubic aluminosilica monoliths with macro-and meso-cylinder pore structures and aluminium contents with $19 \leq \mathrm{Si} / \mathrm{Al}$ $\geq 1$ as effective adsorbents for removal of organic pollutants such as aniline compounds from an aqueous solution. A simple, reproducible, and one-pot synthesis strategy was used to achieve a realistic control over a wide range of mesophase geometries, cylindrical-like pores, and relatively high surface area, yet maintains the long-range structural ordering of aluminosilica monoliths. To better understand the role of the geometry and nanoscale pore orientation of mesostructures, theoretical models have been developed. In addition, the atomic charge distribution in the interior structures was investigated to give insight about the effect of active site surfaces in the enhancement of the adsorption process. The coordination and location of aluminium sites in the frameworks play a key role in the generation of the surface acidity of aluminosilica monoliths, which enhanced the adsorption capacity of the organic pollutants. Our experimental results suggest that the acidity of the adsorbents significantly increased with increasing amounts of aluminium species in the pore framework walls. The natural surfaces of acidic active sites of monoliths strongly induced the removal and adsorption of toxic aromatic amines from wastewater. The relative adsorption affinity of the mesocylinder adsorbent for organic pollutants was decreased in the order of $p$-nitroaniline $<0$-aminophenol < $p$-chloroaniline $<$ aniline. In addition, the thermodynamic studies indicated that these adsorbent monoliths with macroand meso-cylinder pore cavities show promise for the spontaneous removal of organic containments from aqueous water. Finally, we believe our adsorption model will open a new avenue in the development of simple and effective strategy for removal of pollutants and wastewater treatment.
\end{abstract}

Keywords: Nanoadsorbent; Aniline compounds; 3D microscopic geometry; Monoliths

\section{Introduction}

Industry and municipalities use more than about $10 \%$ of the globally accessible runoff and generate a stream of wastewater, which flows or seeps into rivers, lakes, groundwater, or the coastal seas. These wastewaters contain numerous chemical compounds in varying concentrations [1]. In addition, a common problem in many industries is the disposal of large volumes of wastewater containing major classes of these organic compounds, which are mutagenic and carcinogenic, with high toxicological potentials. Water pollution with thousands of industrial and natural chemical compounds is one of the key environmental problems facing humanity and industrial today. Therefore, the development of a simple, fast technology for removal, separation, and determination of the organic contaminates in aquatic life is crucial issue [2]. Among these discharged pollutants, aniline compounds are one of the most important organic intermediates that are widely used in the manufacture of conducting polymers, rubbers, drugs, dyes, and pesticides [3]. The potential use of aniline compounds resulted in their large-scale disposal into wastewater. $p$-Chloroaniline is a highly toxic agent to humans that is absorbed through the skin or through inhalation [4]. However, the non-degradable nature and stability toward light and/or oxidizing agents of polutants complicates the selection of a suitable method for removal. Several methods have been developed to treat the dye-containing effluents, including biological treatment, coagulation / flocculation, ozone treatment, chemical oxidation, membrane filtration, ion exchange, photo-catalysis, and adsorption [5-7]. Pollutants adsorption by solids is considered as a promising and efficient technique for water treatment [8]. Organic clay [9-10], silica gel [11], zeolites [12], montmorillonite [13], resins [14], polymers [15], activated carbons [16], $\alpha-\mathrm{Al}_{2} \mathrm{O}_{3}$ [17], and iron powders [18], have been used as adsorbent for removal of aniline derivatives from aquatic life. Although these solid materials are commonly used as efficient adsorbents for the removal of organic pollutants from contaminated water, particularly activated carbons, the development of new adsorbent materials that can enhance the adsorption capacity and affinity and of reproducible and reversible assays is impressive [4,19-21].

Since the discovery of a novel class of the M41S family of mesoporous molecular sieves, it was found that the incorporation of aluminium into the framework provides materials with acidic active sites. These aluminosilica materials were reported to show an exciting range of applications including catalysis, sensor, membrane filtration $[2,3,22-25]$, despite the existence of the local structural disorder that is being similar to those amorphous alumina and aluminosilicas [26]. On the other hand, the acidity of aluminosilicas surfaces is a key factor in the material applicability. The acidity of these solid materials generally arises from cationic Brønsted or Lewis acid sites that resulted

*Corresponding author: Sherif A. EL-Safty, National Institute for Materials Science (NIMS), 1-2-1 Sengen, Tsukuba-shi, Ibaraki-ken, 305-0047, Japan, Tel:+81-298592135; Fax: +81-298592025; E-mail: sherif.elsafty@nims.go.jp; sherif@aoni.waseda.jp

Received May 18, 2012; Accepted June 20, 2012; Published June 22, 2012

Citation: EL-Safty SA, Khairy M, Ismael M (2012) Nanoadsorbent of Organic Compounds Based on Two- and Three-Dimensional Mesocylinder Monoliths. J Environ Anal Toxicol 2:147. doi:10.4172/2161-0525.1000147

Copyright: (C) 2012 EL-Safty SA, et al. This is an open-access article distributed under the terms of the Creative Commons Attribution License, which permits unrestricted use, distribution, and reproduction in any medium, provided the original author and source are credited. 
from the presence of tetrahedrally coordinated aluminium species $\left(\mathrm{AlO}_{4}^{-}\right)$in the aluminosilicas frameworks [27]. The extent of acidity is dependent on the mechanism formation of aluminosilicas and on nature and the amount of aluminium in the silica matrices. However, the acidity of aluminosilicas results from the charge imbalance created by substitution of a $\mathrm{Si}^{4+}$ atom by an $\mathrm{Al}^{3+}$ atom in the silica-rich host lattice. The $\mathrm{AlO}_{4}$ - units generated this way localize a negative charge that must be compensated by a proton or a cation, and thus aluminosilicas acquire acidic and ion exchange properties. Although, it is reasonably believed that the high aluminium content in aluminosilica frameworks led to increase the acidity of the resultant solid acid aluminosilica materials, the ordering and hydrothermal stability of these materials were drastically decreased with low $\mathrm{Si} / \mathrm{Al}$ ratio [26-29]. Control over the local aluminium structure in frameworks, structural integrity, and thermal/hydrothermal stability with increasing the aluminium content in the mesopore frameworks remains a significant challenge.

Recently, we fabricated 3D cubic Fm3m and hexagonal P6mm aluminosilica mesostructures with uniform and large pores $\leq 10 \mathrm{~nm}$ through direct preparation using Brij $97\left(C_{18} E O_{10}\right)$ templates [30,31]. The significant key features of aluminosilicas are applicability and excellent reusability with thermal and hydrothermal stability. These aluminosilica mesostructures are highly promising candidates for the adsorption of nanoscale molecules (toxic molecules) or colorant dyes. In the current study, hexagonal $p 6 \mathrm{~mm}$ and cubic $F m 3 \mathrm{~m}$ aluminosilica mesocylinder with large cavities have been fabricated. The prepared mesocylinder enable us to study the removal and adsorption of aniline compounds from aqueous solution. Moreover the micro/ meso-structural properties were calculated using theoretical modelling (Scheme 1), in particular the effect of molecular orientation in the functional acid sites. In general, this adsorption model enables the development of simple and effective technique for the removal wastewater treatment.

\section{Materials and Methods}

\section{Chemicals}

All materials were used as produced without further purification. Tetramethylorthosilicate (TMOS) and aluminium nitrate enneahydrate $\left(\mathrm{Al}\left(\mathrm{NO}_{3}\right)_{3} \cdot 9 \mathrm{H}_{2} \mathrm{O}\right), \quad p$-nitroaniline $\left(p-\mathrm{NO}_{2}-\mathrm{Ar}-\mathrm{NH}_{2}\right), \quad o$-aminophenol $\left(o-\mathrm{NH}_{2}-\mathrm{Ar}-\mathrm{OH}\right), p$-chloroaniline $\left(p-\mathrm{Cl}-\mathrm{Ar}-\mathrm{NH}_{2}\right)$, and aniline (Ar$\left.\mathrm{NH}_{2}\right)$, the Brij $97\left(\mathrm{C}_{18} \mathrm{EO}_{10}\right)$ surfactants, and $\mathrm{C}_{\mathrm{n}}$-alkane were obtained from Sigma-Aldrich Company Ltd. USA. The solublizing alkane agent such as octane $\left(\mathrm{C}_{8} \mathrm{H}_{18}\right)$ and dodecane $\left(\mathrm{C}_{12} \mathrm{H}_{26}\right)$ was obtained from Wako Company Ltd. Osaka, Japan.

\section{Preparation of mesocylinder aluminosilica monoliths}

The simple preparation for hexagonal and cubic Fm $3 m$ monolithic aluminosilica adsorbents was based on the direct templating of the lyotropic and microemulsion liquid crystalline phase of the Brij 97 surfactant, respectively. In this direct preparation of cubic $F m 3 m$ aluminosilica monoliths, for example, at the $\mathrm{Si} / \mathrm{Al}$ ratio of $9(\mathrm{w} / \mathrm{w})$ and at a Brij 97/ tetramethylorthosilicate (TMOS) ratio of $0.75(\mathrm{w} / \mathrm{w})$, the precursor solution [1.5 $\mathrm{g}$ of Brij 97, $0.75 \mathrm{~g}$ dodecane, $2 \mathrm{~g}$ TMOS, $0.569 \mathrm{~g} \mathrm{Al}\left(\mathrm{NO}_{3}\right)_{3}, 2 \mathrm{~g} \mathrm{H}_{2} \mathrm{O}-\mathrm{HCl}($ at $\mathrm{pH}=1.3)$, and $10 \mathrm{~g}$ of ethanol] was stirred for $30 \mathrm{~min}$ to form a homogenous sol-gel solution. The resulting optical gel-like mixture was placed in a graduate ingot. The mixture subsequently acquired the shape and size of the cylindrical casting vessel. The monoliths were gently dried at room temperature for $2 \mathrm{~h}$ and then allowed to stand in a tightly closed ingot for $1 \mathrm{~d}$ to complete the drying process. To obtain membrane samples with aluminium contents at $\mathrm{Si} / \mathrm{Al}$ ratio of $19,4,2.33$ and 1 , the composition of $\mathrm{Al}\left(\mathrm{NO}_{3}\right)_{3}$ was varied from $0.7 \times 10^{-3}$ to $13.6 \times 10^{-3}$ mole ratio (Table 1 ). The mass ratio of surfactant to alkane was kept at 2:1 for all syntheses of the mesoporous aluminosilica membranes. The organic moieties were removed by calcination at $550^{\circ} \mathrm{C}$ in air for $5 \mathrm{~h}$. The hexagonal $P 6 \mathrm{~mm}$ aluminosilica monoliths was fabricated using a lyotropic system of Brij 97 template (i.e., without addition of dodecane to the composition domains). The calcined aluminosilica cubic $F m 3 m$ and hexagonal $P 6 \mathrm{~mm}$ monoliths clearly had stable and tough morphology. The transparency of the membrane was lost during calcination, as previously reported for mesoporous monoliths [30-31].

\section{Batch adsorption of aniline compounds}

The batch adsorption of the anilines $p$-nitroaniline $\left(p-\mathrm{NO}_{2}-\mathrm{Ar}-\right.$ $\left.\mathrm{NH}_{2}\right), \quad o$-aminophenol $\left(o-\mathrm{NH}_{2}-\mathrm{Ar}-\mathrm{OH}\right), p$-chloroaniline $(p$-Cl-Ar$\left.\mathrm{NH}_{2}\right)$, and aniline $\left(\mathrm{Ar}-\mathrm{NH}_{2}\right)$ onto $(0.2 \mathrm{~g})$ aluminosilica monoliths was performed in an aqueous solution at different temperatures $\left(30^{\circ} \mathrm{C}\right.$ to $45^{\circ} \mathrm{C}, \pm 0.1^{\circ} \mathrm{C}$ range). The adsorption process was performed using a shaker thermostat, where the shaking rate was kept constant for all experiments. The initial concentration of adsorbates in the range of $5 \times 10^{-3} \mathrm{~mol} / \mathrm{L}$ to $8 \times 10^{-4} \mathrm{~mol} / \mathrm{L}$ was measured using a Shimadzu 3700 model solid-state ultraviolet-visible spectrophotometer at specific wavelengths of 287, 289, 289, and $262 \mathrm{~nm}$ for $p-\mathrm{NO}_{2}-\mathrm{Ar}-\mathrm{NH}_{2}, o-\mathrm{NH}_{2}-$ Ar-OH, $p-\mathrm{Cl}-\mathrm{Ar}-\mathrm{NH}_{2}$, and $\mathrm{Ar}-\mathrm{NH}_{2}$ molecules, respectively.

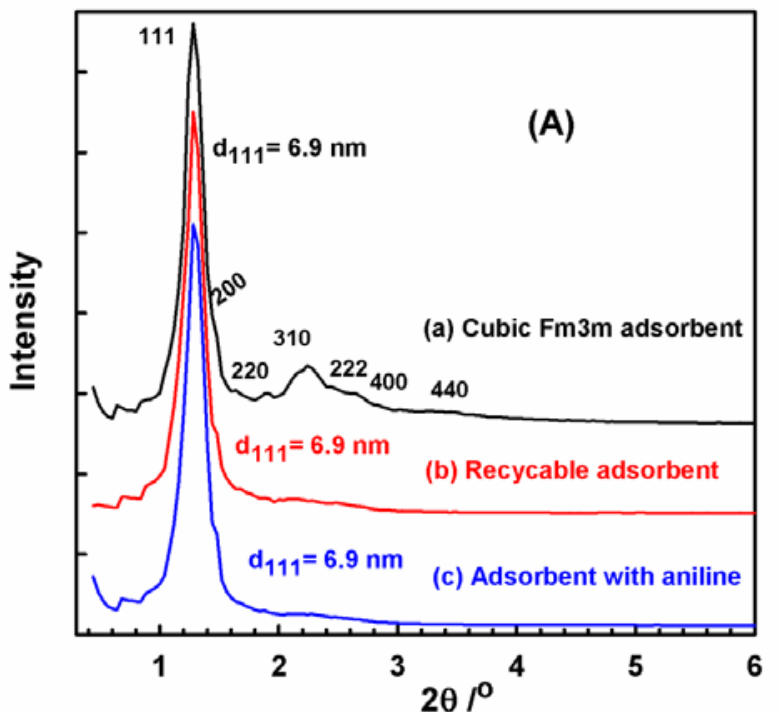

Scheme 1: 3D cubic Fm3m geometrical modeling of mesoscale structures of the aluminosilica (A, B) and the model of charged cluster aluminosilica monoliths with $\mathrm{p}-\mathrm{Cl}-\mathrm{Ar}-\mathrm{NH}_{2}$ adsorption (C).

\begin{tabular}{|l|l|l|l|l|l|l|l|}
\hline \multirow{3}{*}{ Si/A } & \multicolumn{3}{|l|}{ Synthesis conditions } & \multicolumn{4}{|c|}{ Structure parameters } \\
\cline { 2 - 9 } & $10^{2} . \mathrm{T} /$ mole & $\begin{array}{l}\left(10^{3}\right) \mathrm{Al}\left(\mathrm{NO}_{3}\right)_{3} / \\
\text { mole }\end{array}$ & $\begin{array}{l}\text { Brij 97/TMOS } \\
(\mathrm{w} / \mathrm{w})\end{array}$ & $\begin{array}{l}a_{\text {Fm3m }} \\
\mathrm{nm}\end{array}$ & $\begin{array}{l}\mathrm{S}_{\mathrm{BET}} \\
\mathrm{m}^{2} / \mathrm{g}\end{array}$ & $\begin{array}{l}\mathrm{PSD} \\
\mathrm{nm}\end{array}$ & $\begin{array}{l}\mathrm{Vp} \\
\mathrm{cm}^{3} / \mathrm{g}\end{array}$ \\
\hline 19 & 1.31 & 0.7 & 0.75 & 11.95 & 700 & 6.2 & 1.09 \\
4 & 1.31 & 3.4 & 0.75 & 12.3 & 540 & 6.1 & 0.95 \\
2.3 & 1.31 & 5.8 & 0.75 & 12.6 & 435 & 6.0 & 0.91 \\
1.0 & 1.31 & 13.6 & 0.75 & 13.2 & 380 & 5.9 & 0.89 \\
\hline
\end{tabular}

Table 1: Synthesis conditions, structural and textural parameters of cubic Fm3m aluminosilica membrane adsorbents fabricated using microemulsion phases of Bri 97 as soft templates with a wide range of $\mathrm{Si} / \mathrm{Al}$ mole ratios. Unit lattice constant $\left(a_{\mathrm{Fm} 3 \mathrm{~m}}=\mathrm{d}_{111} \sqrt{3}\right)$, BET surface area $\left(\mathrm{S}_{\mathrm{BET}}\right)$, and NLDFT pore size distribution (PSD) and pore volume $(\mathrm{Vp})$ are indicated. 
Citation: EL-Safty SA, Khairy M, Ismael M (2012) Nanoadsorbent of Organic Compounds Based on Two- and Three-Dimensional Mesocylinder Monoliths. J Environ Anal Toxicol 2:147. doi:10.4172/2161-0525.1000147

\section{Analysis of mesocylinder alumina adsorbents}

Small angle powder X-ray diffraction (XRD) patterns were measured by using a $18 \mathrm{~kW}$ diffractometer (Bruker D8 Advance) with monochromated $\mathrm{CuKa}$ radiation and with scattering reflections recorded for $2 \theta$ angles between $0.1^{\circ}$ and $6.5^{\circ}$ corresponding to $\mathrm{d}$-spacing between 88.2 and $1.35 \mathrm{~nm}$. First, the powder samples were ground and spread on a sample holder. The samples were scanned in the range from $2 \theta=0.1^{\circ}-6.5^{\circ}$ with step size of $0.02^{\circ}$. To confirm the resolution of the diffraction peaks with standard reproducibility in 2 -theta $( \pm 0.005)$, the sample measurement was recorded by using both graphite monochromator and Göbel mirror detectors. Both detectors were used to generate focusing beam geometry and parallel primary beam. The sample measurement was repeated three times under rotating at various degrees $\left(15^{\circ}, 30^{\circ}\right.$ and $\left.45^{\circ}\right)$.

$\mathrm{N}_{2}$ adsorption-desorption isotherms were measured using a BELSORP MIN-II analyzer (JP BEL Co., Ltd.) at $77 \mathrm{~K}$. The pore size distribution was determined from the adsorption isotherms by the nonlocal density functional theory (NLDFT). The specific surface area $\left(S_{\mathrm{BET}}\right)$ was calculated using multi-point adsorption data from the linear segment of the $\mathrm{N}_{2}$ adsorption isotherms by the Brunauer-EmmettTeller (BET) theory. Before the $\mathrm{N}_{2}$ isothermal analysis, all prepared samples were pretreated at $200{ }^{\circ} \mathrm{C}$ for $8 \mathrm{~h}$ under a vacuum until the pressure was equilibrated to $10^{-3}$ Torr.

To investigate the acidic properties of aluminosilica samples, $\mathrm{NH}_{3}$ temperature-programmed desorption $\left(\mathrm{NH}_{3}-\mathrm{TPD}\right)$ was measured by using a BEL-Japan TPD-1S system with a quadrupole mass spectrometer. ${ }^{27} \mathrm{Al}$ magic-angle spinning (MAS) nuclear magnetic resonance (NMR) spectroscopy was also recorded using a Bruker AMX-500 spectrometer. ${ }^{27} \mathrm{Al}$ NMR spectra were measured at a frequency of $125.78 \mathrm{MHz}$ with a $90^{\circ}$ pulse length of $4.7 \mu \mathrm{s}$. For all samples, the repetition delay was $64 \mathrm{~s}$ with a rotor spinning at $4 \mathrm{kHz}$ for ${ }^{27} \mathrm{Al} \mathrm{NMR}$. The chemical shift scale was externally adjusted to be zero for the ${ }^{27} \mathrm{Al}$ signal using an aqueous solution $(1 \mathrm{~N})$ of $\mathrm{Al}\left(\mathrm{NO}_{3}\right)_{3}$.

High-resolution transmission electron microscopy (HRTEM) was performed using a JEOL JEM model 2100F microscope. HRTEM was conducted at an acceleration voltage of $200 \mathrm{kV}$ to obtain a lattice resolution of $0.1 \mathrm{~nm}$. The HRTEM images were recorded using a charge-coupled device camera. TEM was carried out at a camera length of $80 \mathrm{~cm}$ and a spot size of $1 \mathrm{~nm}$. In the HRTEM ccharacterizations, the sample was dispersed in ethanol solution using an ultrasonic cleaner, and then dropped on a copper grid. Before inserting the samples into the HRTEM column, the grid was vacuum dried for $20 \mathrm{~min}$.

FESEM images were measured by a field-emission scanning electron microscopy (Hitachi S-4300). Before insertion into the chamber the adsorbent powder substrates were fixed on a SEM stage using carbon tapes. The Pt films were deposited on adsorbent substrates at room temperature by using an ion-sputter (Hitachi E-1030). The distance between the target and the adsorbent substrate was $5.0 \mathrm{~cm}$. The sputtering deposition system used for the experiments consists of a stainless steel chamber, which was evacuated down to $8 \times 10^{-5} \mathrm{~Pa}$ with a turbomolecular pump backed up by a rotary pump. Before sputtering deposition, the Pt target (4 in. diameter, purity 99.95\%) was sputter cleaned in pure Ar. The Ar working pressure $\left(2.8 \times 10^{-1} \mathrm{~Pa}\right)$, the power supply $(100 \mathrm{~W})$ and the deposition rate were kept constant throughout these investigations. Moreover, to better record the SEM images of aluminosilica samples, the SEM micrographs were operated at $20 \mathrm{keV}$.

\section{Results and Discussion}

\section{Formation of hexagonal and cubic adsorbents}

In the microemulsion mesophase systems, addition of an alkane with long alkyl chain lengths $\left(\mathrm{C}_{12}\right.$-alkane) to the lyotropic hexagonal (surfactant/TMOS/aluminium salt) composition substantially affected the formation of the 3D mesophase and the enlargement of pore sizes of the aluminosilica mesostructures [30]. In the current report, the solubilisation of alkane into the hexagonal phase domains of Brij 97 resulted in the hexagonal $P 6 m m$-cubic $F m 3 m$ phase transition with shape- and size-controlled cylinder pores, as evidenced from the XRD patterns (Figure 3A). Our simple method in the context of synthesis time (on the order of minutes) and composition domains shows key facts of the fabrication of various types of surfactant/silica mesophases. In fact, the instant preformed liquid crystalline phases provide high control over the geometrical symmetry, preferential mesophase
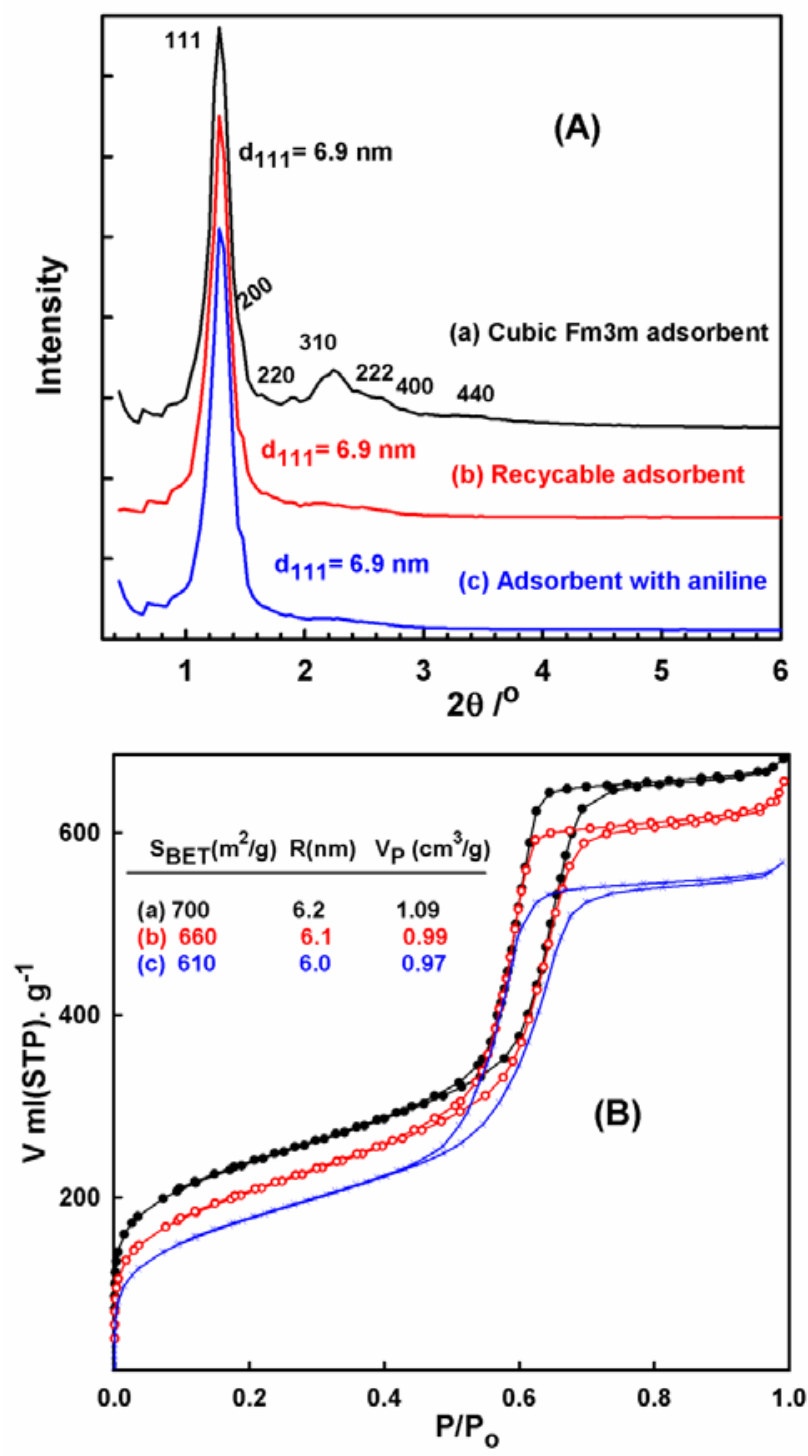

Figure 1: XRD patterns of cubic Fm3m aluminosilicate monoliths with $\mathrm{Si} / \mathrm{A}$ mole ratios of 19 (a),Cubic Fm3m aluminosilica adsorbents after $3^{\text {rd }}$ reuse cycle (b) and after adsorption and immobilization of aniline into the inner pores (c). 

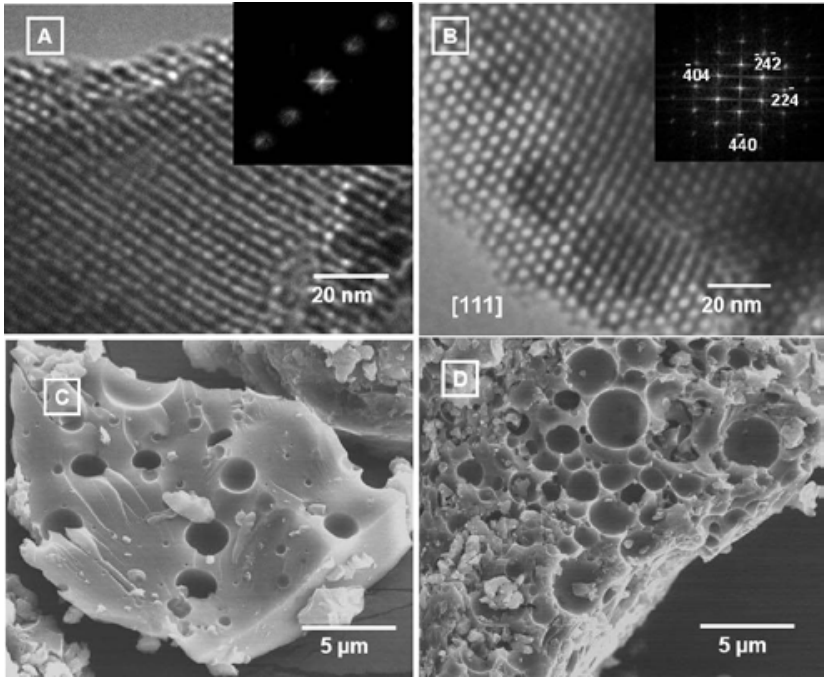

Figure 2: Representative HRTEM and FTD (inserts) patterns of hexagonal P6mm (A) and cubic $F m 3 m$ (B) aluminosilica monoliths with $\mathrm{Si} / \mathrm{Al}$ mole ratios of 19. (C,D) SEM micrographs of both aluminosilica adsorbent monolithswith $\mathrm{Si} /$ Al mole ratios of 2.3 .

organization, and structural stability on the final aluminosilica replicas of fabricated $2 \mathrm{D}$, and $3 \mathrm{D}$ phase structures. In general, the fabrication strategy of mesocylinder aluminosilicas is highly promising for easyto-use and removal for organic contaminates.

The XRD patterns of the monoliths with low aluminium content $(\mathrm{Si} / \mathrm{Al}<4)$ show well-resolved diffraction peaks that tentatively result in the assignment of ordered cubic $F m 3 m$ geometries. In turn, the partial collapse of mesostructures may be due to a lack of long-range crystallographic order or to the finite size effects of aluminosilicas inside the mesopore structures, as evidenced from the low-intensity reflections with high $\mathrm{Al}$ contents. However, the addition of a large amount of aqueous aluminium salt to the synthesis composition domains increases the polar volume fractions, thus increasing the unitcell constants $\left(a_{\mathrm{Fm} 3 \mathrm{~m}}=\mathrm{d}_{111} \sqrt{ } 3\right)$ of the cubic structures. [31]. Our findings reveal that the high aluminium salt in the composition synthesis domains might change the micellar aggregate sizes and volume fractions of the sphere core and the corona of the Brij 97 surfactant at specific synthesis compositions. Moreover, the addition of swelling agent $\left(\mathrm{C}_{12}{ }^{-}\right.$ alkane) and co-surfactant (ethanol) under synthesis conditions leads to the formation of large and open cylindrical mesostructures.

The $\mathrm{N}_{2}$ adsorption isotherms (Figure 1B) of aluminosilica monoliths showed an $\mathrm{H}_{2}$-type hysteresis loop and well-defined steepness of isotherms, indicating that uniform cylinder-like pore structures were characteristic of the cubic aluminosilica monoliths. The adsorption branches significantly shifted toward a lower relative pressure (P/ $\mathrm{P}_{\mathrm{o}}$ ) with increasing aluminium contents. The lower closure point of the hysteresis loop was significantly depended on the Al content; this indicates the columnar-induced stepwise desorption in the open tubular pores, leading to more easier diffusion, such open tubularlike pore scaffolds, than that of ink bottle pore materials with narrow entrances [32]. With both hexagonal and cubic $F m 3 m$, the decrease in these textural parameters was observed because of the structural ordering degradation with high aluminium contents of monoliths. Our findings reveal that the porosity and order structure maintained not only after aniline adsorption but also after several times of reuse and cycles, indicating the stability of mesocylinder aluminosilica structures.
Based on the $\mathrm{N}_{2}$ isothermal results, the cylindrical aluminosilica monoliths were observed to have the appreciable textural parameters of specific surface area $\left(\mathrm{S}_{\mathrm{BET}}\right)$, mesopore volume, and tuneable pore diameters [32,33].

The transmission electron microscopy (TEM) images (Figure 2) show that the $2 \mathrm{D}$ hexagonal and $3 \mathrm{D}$ cubic mesoscopic qualities of aluminosilica monoliths still retained their long-range structural ordering over a large area even for samples with $\mathrm{Si} / \mathrm{Al}$ ratios as high as 4 . The overall TEM lattice images and the corresponding Fourier transform diffractogram (FTD) patterns (inserts) indicate the formation of hexagonal $P 6 \mathrm{~mm}$ and cubic $\mathrm{Fm} 3 \mathrm{~m}$ structures. With low silica contents $(1.5 \leq \mathrm{Si} / \mathrm{Al} \leq 1)$, representative TEM images reveal a short-range ordering or even wormlike mesopore channels that are interconnecting in large size domains. These hexagonal and cubic monoliths with pore cavities show promise for the removal and decontamination of aniline compounds from aqueous water (see below). The coordination state of the aluminium species was investigated using ${ }^{27} \mathrm{Al} \mathrm{NMR} \mathrm{(data} \mathrm{not} \mathrm{shown).} \mathrm{In} \mathrm{all} \mathrm{the} \mathrm{aluminosilica}$ samples $(19 \leq \mathrm{Si} / \mathrm{Al} \leq 1)$, two ${ }^{27} \mathrm{Al}$ peaks centered at the chemical shift of -1 and $58 \mathrm{ppm}$, indicating the existence of octahedral $\left(\mathrm{Al}^{\mathrm{VI}}, \mathrm{AlO}_{6}\right.$, extra framework) and tetrahedral $\left(\mathrm{Al}^{\mathrm{IV}}, \mathrm{AlO}_{4}\right.$, framework) aluminium sites, respectively. Tetrahedrally coordinated aluminium sites were significantly increased with increasing aluminium contents in the mesoporous monoliths. The coordination and location of aluminium sites in the frameworks play a key role in the generation of the surface acidity of aluminosilica monoliths, which enhanced the adsorption capacity of the aniline pollutants [34].

High-resolution scanning electron microscopy (HRSEM) micrographs reveal that the both hexagonal and cubic aluminosilicas fabricated with high aluminium contents ( $\mathrm{Si} / \mathrm{Al}$ ratios $\leq 4$ ) possessed large particle sizes (5-30 $\mu \mathrm{m}$ diameter) and had plate-like particles with dense macroporous voids (open holes) on their surface morphology, which are attributed to structural defects with the instability of aluminium in the framework of monoliths at high-temperature calcination. The size of these morphological defects is not uniform (distributes between $500 \mathrm{~nm}$ and $2.5 \mu \mathrm{m}$ ) and their shapes are irregular. These adsorbent monoliths with mesocyliner pore cavities show promise for the removal and decontamination of organic containments from aqueous water.

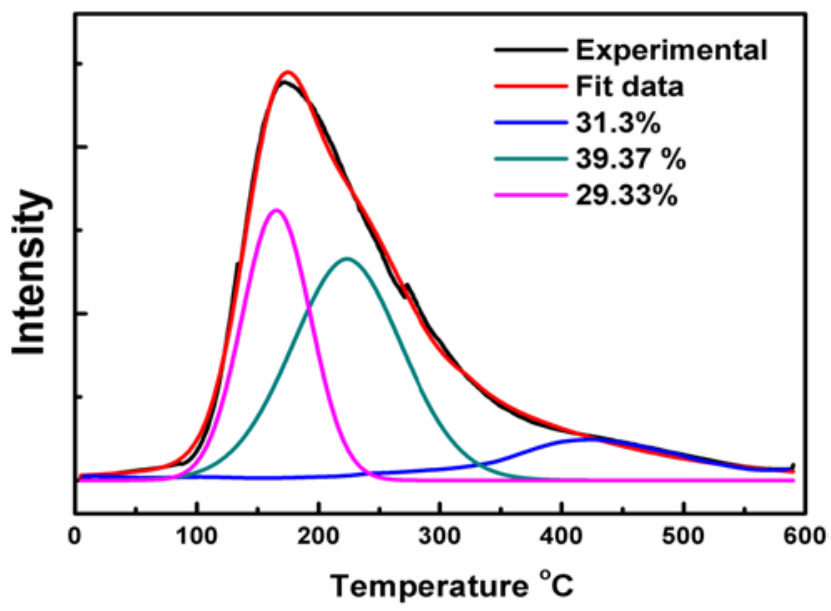

Figure 3: $\mathrm{NH}_{3}$-TPD spectra and the deconvolution of each peak of the cubic Fm3m aluminasilicateadsorbents. 
To quantitatively determine the amount and strength of acid sites of mesoporous aluminosilica, TPD measurements were performed. The TPD profiles (Figure 3) show two main peaks of $\mathrm{NH}_{3}$ desorption at approximately $200^{\circ} \mathrm{C}$ and a small, broad intensity peak in the range of $400{ }^{\circ} \mathrm{C}$ to $500{ }^{\circ} \mathrm{C}$. These peaks indicated that two types of acid sites were characterized by aluminosilica monoliths with all $\mathrm{Si} / \mathrm{Al}$ ratios, as evidenced by the deconvolution analysis of the desorption curve. The peaks at approximately $200{ }^{\circ} \mathrm{C}$ and $450^{\circ} \mathrm{C}$ were deconvoluted using the Gaussian function, with temperature as the variant. The components of the peaks at approximately $200{ }^{\circ} \mathrm{C}$ and $450{ }^{\circ} \mathrm{C}$ were $68.7 \%$ and $31.3 \%$, respectively. These component ratios indicated that ammonia was desorbed from the weak "Lewis" and mildly strong "Bronsted" acid sites of the $\mathrm{OH}$-groups of aluminosilica adsorbents. Furthermore, the number of acid sites increased with the amount of aluminium which is in agreement with recent reports [33]. The enhancement of surface acidity might result in a strong interaction between the surface functional groups of the adsorbents and the adsorbates. Such interactions between the pollutants and aluminosilicas occurred on the bases of the cluster model of spherical aluminosilicates $\left(\mathrm{AlSi}_{4} \mathrm{O}_{12}\right)$ consisting of two types of oxygen linkages (see below)

\section{Theoretical modelling of $3 \mathrm{D}$ geometrical orientation of mesocylinder adsorbents}

The theoretical modelling of aluminosilicate structure was carried out to investigate significant features on the adsorbents as follows:

1) charge distribution density of $\mathrm{Si}, \mathrm{O} \& \mathrm{Al}$ atoms,

2) $\mathrm{Si}$ and $\mathrm{Al}$ atom arrangements at the edges of cubic $\mathrm{Fm} 3 \mathrm{~m}$ symmetry that can form inner mesopore surfaces $(\sim 6.2 \mathrm{~nm})$,

3) the cross-linked frameworks containing O-bridge $\mathrm{Si}$, and O-bridge Al,

4) the bond orientation and formation between $\mathrm{Al}, \mathrm{O}$, and $\mathrm{H}$ atoms, and

5) the key factors of generation the surface acidity.

The charge distribution and orbital shape were also calculated to give insight about the effect of $\mathrm{Al}$ sites on the adsorbent acidity. Modelling Calculations were carried out using semiempirical MP3 methods implemented on Gaussian03 program package (Scheme 1). This software is developed by Gaussian Inc. [35]. The crystal structure was defined on the bases of the cluster model of spherical aluminosilicates $\left(\mathrm{AlSi}_{4} \mathrm{O}_{12}\right)$ which consists of two types of oxygen linkage (i.e., oxygen-bonded to $\mathrm{Si}$ or $\mathrm{Al}$ and siloxane species, respectively). The first group is mainly responsible for the creation of Brönosted acid sites. The siloxane orientation may contribute to the crystal shape formation. This spherical aluminosilicates $\left(\mathrm{AlSi}_{4} \mathrm{O}_{12}\right)$ cluster unit was used for construction of nano-scale alumiosilicate model (Scheme1). Furthermore, Scheme 1C shows the electron density distribution on the structural model of aluminosilicate. It can be observed that the atoms oriented at the edges of cubic Fm $3 \mathrm{~m}$ symmetry can form inner mesopore surfaces $(\sim 6.2 \mathrm{~nm})$, as evidenced from $\mathrm{N}_{2}$ isotherms (Figure 1B, Table 1). The calculated atomic charges (Scheme 1C) of $\mathrm{Al}, \mathrm{Si}$, O-siloxane cross-linked frameworks, O-bridge $\mathrm{Si}$, and O-bridge $\mathrm{Al}$ are $1.48,1.35,-0.6,-0.57,-0.99$, respectively. It is clear that the oxygen atoms in the $\mathrm{Si}-\mathrm{O}-\mathrm{Al}$ linkages are more negative than other oxygen in the linkage species, indicating to the high acid sites in this linkages compared with other sites in the frameworks, as evidenced from ${ }^{27} \mathrm{Al}$ NMR spectra (data not shown). However, the formation of the coordination state of the aluminium species in four- $\left(\mathrm{Al}^{\mathrm{IV}}, \mathrm{AlO}_{4}\right.$, framework $)$ and six- $\left(\mathrm{Al}^{\mathrm{VI}}, \mathrm{AlO}_{6},\right)$ coordinate environments around -1 , and $45 \mathrm{ppm}$, respectively, indicates the existence of different bonds between $\mathrm{Al}, \mathrm{O}$, and $\mathrm{H}$. The coordination and location of aluminium sites in the frameworks are key determinants in the generation of the surface acidity of adsorbents, leading to create strong interaction between $\mathrm{Al}-\mathrm{OH}$ or $\mathrm{Si}-\mathrm{OH}$ surfaces and organic molecules.

\section{Adsorption and removal of organic contaminants from aqueous water}

The removal of aniline pollutants using aluminosilica nanoadsorbent was conducted through batch contact-time experiments in an aqueous solution. The adsorbed amount as a function of the exposure time of the aniline contaminates to the monoliths was studied using UV-vis spectroscopy. The adsorption amount $\left(\mathrm{q}_{\mathrm{e}}, \mathrm{mmol} . \mathrm{g}^{-1}\right)$ of the aniline molecules at the equilibrium step was determined according to the following equation [36]:

$$
q_{e}=\left(C_{o}-C_{e}\right) V / m
$$

where $\mathrm{V}$ is the solution volume $(\mathrm{L}) ; \mathrm{m}$ is the mass of monolithic adsorbents $(\mathrm{g}) ; \mathrm{C}_{\mathrm{o}}$ and $\mathrm{C}_{\mathrm{e}}$ are the initial and equilibrium adsorbate concentrations, respectively. Figure $4 \mathrm{~A}$ shows the time-rate dependence
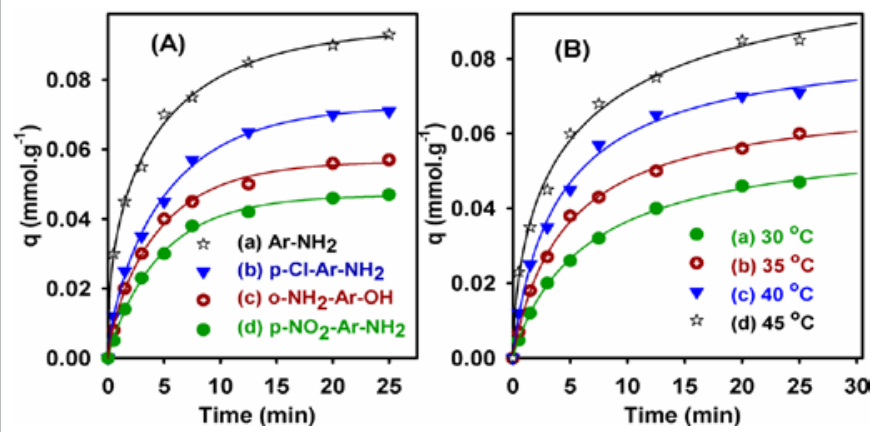

Figure 4: Time-rate dependence of the adsorption amount of organic pollutants $\left[1.6 \times 10^{-3} \mathrm{M}\right](\mathrm{A})$. Effect of temperature $\left({ }^{\circ} \mathrm{C}\right)$ on the time-rate dependence curve of the adsorption assay of p-Cl-Ar- $-\mathrm{NH}_{2}$ (III) onto [10 g/L] mesocylinderaluminosilicate-based adsorbents with a Si/Al ratio of 1.0.

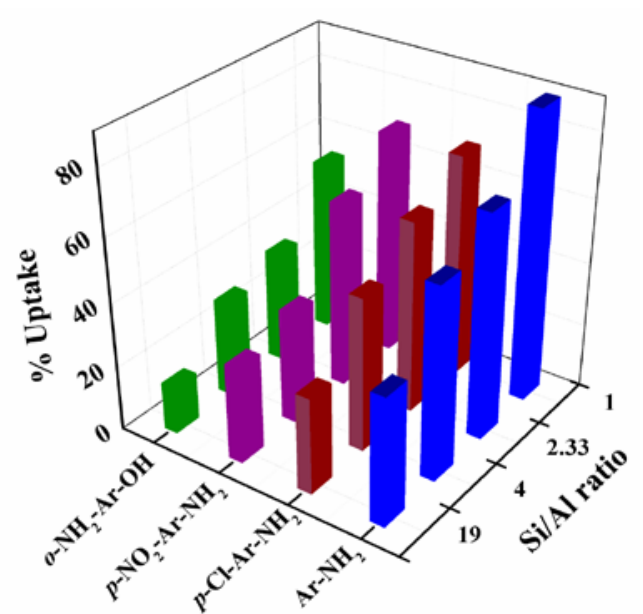

Figure 5: Representative organic compounds uptake onto [10 g/L] hexagonal $\mathrm{P} 6 \mathrm{~mm}$ aluminosilica adsorbents (monoliths) fabricated with different Si/Al ratios. Batch contact-time experiments were conducted at $40^{\circ} \mathrm{C}$, equilibrium time, shaking rate, and at an adsorbate concentration $\left(1.6 \times 10^{-3} \mathrm{M}\right)$. 
of the adsorption amount of molecule solutes using mesocylinder cubic $\mathrm{Fm} 3 \mathrm{~m}$ monolithic adsorbents at specific conditions (i.e., 40 ${ }^{\circ} \mathrm{C}$, adsorbent dose of $10 \mathrm{~g} / \mathrm{L}$, adsorbate concentration of $1.6 \times 10^{-3}$ $\mathrm{mol} / \mathrm{L}$, and constant shaking rate). Figure $4 \mathrm{~B}$ shows the temperaturedependent kinetic response of the $p-\mathrm{Cl}-\mathrm{Ar}-\mathrm{NH}_{2}$ adsorption. Results indicated that the increase in the temperature resulted in the increased activation energy of the adsorbates in the aqueous phase and consequently enhanced the adsorption amounts.

The percentage uptake $(\% \mathrm{U})$ of the adsorbate solutes at the adsorption equilibrium was calculated using the following equation [25,37]:

$$
\% U=\left(C_{o}-C_{e} / C_{o}\right) \times 100
$$

Results show (Figure 5) that percentage uptake $(\% \mathrm{U})$ of organic pollutants onto both hexagonal and cubic adsorbents was increased in the order of $p-\mathrm{NO}_{2}-\mathrm{Ar}-\mathrm{NH}_{2}<o-\mathrm{NH}_{2}-\mathrm{Ar}-\mathrm{OH}<p-\mathrm{Cl}-\mathrm{Ar}-\mathrm{NH}_{2}<$ $\mathrm{Ar}-\mathrm{NH}_{2}$. Based on this adsorption behavior, the lower adsorption effectiveness of these organic pollutants was clearly consistent with the higher basicity (i.e., higher $\mathrm{pK}_{\mathrm{a}}$ ) of these adsorbates, except with $o-\mathrm{NH}_{2}-\mathrm{Ar}-\mathrm{OH}$. However, the $\mathrm{pK}_{\mathrm{a}}$ values are 4.6, 3.97, 9.7, and 1.01 for Ar- $\mathrm{NH}_{2}, p-\mathrm{Cl}-\mathrm{Ar}-\mathrm{NH}_{2}, o-\mathrm{NH}_{2}-\mathrm{Ar}-\mathrm{OH}, p-\mathrm{NO}_{2}-\mathrm{Ar}-\mathrm{NH}_{2}$ molecules, respectively. The finding trends, in general, are not in accordance with well-known adsorption behaviour, in which stronger basic properties of aniline compounds (higher $\mathrm{pK}_{\mathrm{a}}$ ) result in a higher adsorption value. The negative correlation adsorption behaviour of $o-\mathrm{NH}_{2}-\mathrm{Ar}-\mathrm{OH}$ with its $\mathrm{pK}_{\mathrm{a}}$ value may be attributed to the high interaction affinity through the $\mathrm{NH}_{2}-$ and $\mathrm{OH}$-groups of the adsorbate molecule with the $\mathrm{OH}-$ groups of the solid adsorbents (Figure 5).

The fraction of the coverage adsorbent surfaces $\left(f_{c}, \mathrm{~g} / \mathrm{m}^{2}\right)$ occupied by the organic molecules (Figure 6) was calculated according to the following equation [37]:

$$
f_{\mathrm{c}}=\mathrm{M} \beta / \mathrm{S}
$$

Where $M$ is the molecular area of organic molecules of $60-68 \AA^{2}$, $\mathrm{S}\left(\mathrm{m}^{2} / \mathrm{g}\right)$ is the surface area of the monolithic adsorbents, and $\beta$ is the number of molecules adsorbed per unit area of mesocage adsorbents. However, $\beta$ can be calculated as follows: $\beta=\left(q_{e} / S\right) \times N_{A}$, where $N_{A}$ is Avogadro's number $\left(6.02 \times 10^{23} \mathrm{~mol}^{-1}\right)$. Figure 6 shows that the $f_{\mathrm{c}}$ values were significantly affected by the active functional acid sites, mesocylinder geometries and structural ordering.

Results revealed that the adsorption uptake and the coverage adsorbent surfaces depend on the amount of surface functional groups (Figures 5,6). All Lewis acid sites might transform into Brönsted acid sites because of the adsorption of organic molecules onto the aluminosilica monoliths in aqueous solutions $[34,36]$. The tendency of organic molecules to coordinate with Lewis acid sites is minimal. The number of Brönsted acid sites for aluminosilica monolith adsorbents is the key factors for the enhanced adsorption uptake with high $\mathrm{Al}$ contents. The adsorption amount of adsorbate molecules on the monolithic adsorbents also depends on the extent of the aluminium surface chemistry of the aluminosilica structures (Figures 5,6 and Scheme 1). However, the functional aluminium active sites of fouror six-coordinate species contribute to adsorbate molecule binding. Such a synergistic interaction did not show significant alteration of the chemical properties of the active aluminium species, as evidenced by the ${ }^{27} \mathrm{Al}$ NMR spectra recorded after adsorption assays (data not shown). The results show that the increase in $\mathrm{Al}^{\mathrm{IV}} / \mathrm{Al}^{\mathrm{VI}}$ ratios results in an enhanced adsorption amount of the pollutants. This finding indicates that the organic molecules might readily be adsorbed onto

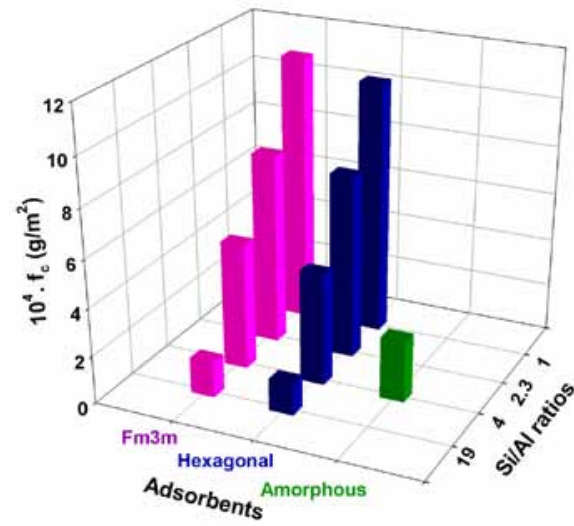

Figure 6: The fraction of the coverage of adsorbent surfaces $(A)$ of $p-\mathrm{NO}_{2}$ Ar- $\mathrm{NH}_{2}\left(1.6 \times 10^{-3} \mathrm{M}\right)$ onto ordered cubic $\mathrm{Fm} 3 \mathrm{~m}$, hexagonal aluminosilicate monoliths $(10 \mathrm{~g} / \mathrm{L})$ with different Si/Al ratios, and onto amorphous aluminosilica powders that were commercially supplied with an Si/Al mole ratio of 4 and at $40^{\circ} \mathrm{C}$

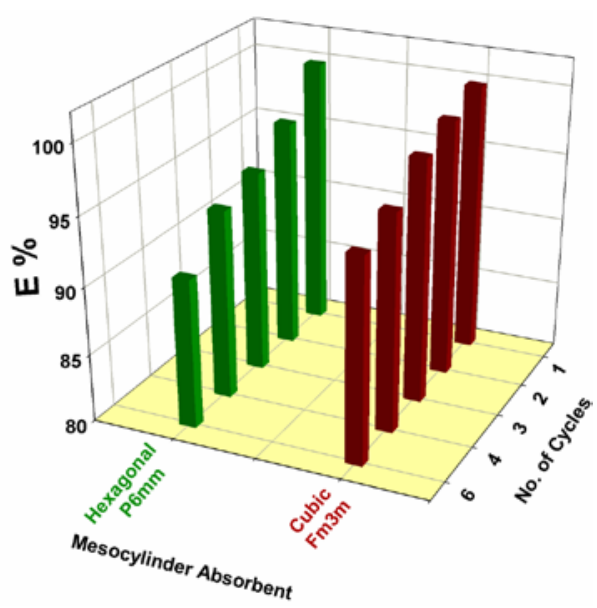

Figure 7: Reusability study of up to six times for the removal assay of [1.6 $x 10^{-3} \mathrm{M}$ ] p-Cl-Ar- $\mathrm{NH}_{2}$ onto [10 g/L] hexagonal and cubic Fm3maluminosilica adsorbents fabricated with a Si/Al ratio of 1 at $40^{\circ} \mathrm{C}$. Note that the efficiency $(\mathrm{E})$ was calculated from the \% ratio of the uptake $(\% \mathrm{U})$ per reuse cycle $(\mathrm{No}$.$) and$ the initial uptake obtained from the initial use of the adsorbents

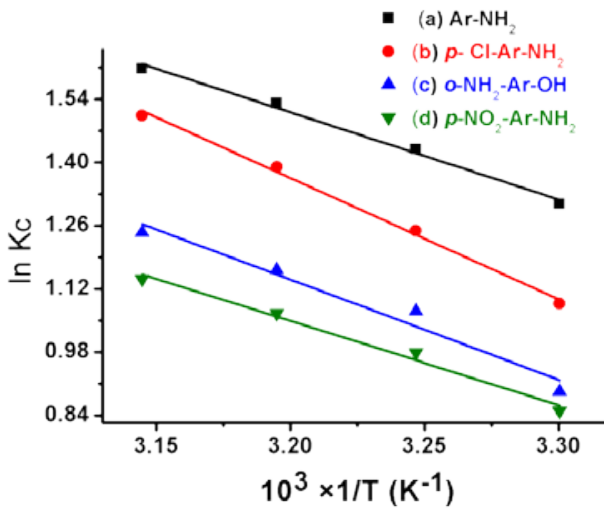

Figure 8: Illustration of the relationship plot between In $K c$ against $1=T$ of the adsorption of the organic pollutants $\left[1.6 \times 10^{-3} \mathrm{M}\right]$ onto $[10 \mathrm{~g} / \mathrm{L}]$ hexagonal aluminosilica monoliths with $\mathrm{Si} / \mathrm{Al}$ ratio of 1.0 . 
monoliths that show highly tetrahedral $\left(\mathrm{Al}^{\mathrm{IV}}, \mathrm{AlO}_{4}^{-}\right.$, framework) aluminium sites.

Furthermore, the mesostructural geometries and 3D dimensions of the aluminosilica adsorbents have significant effects on the overall adsorption uptake of organic molecules. Our findings revealed that the ordered pore geometry had higher adsorption uptake of pollutants than the amorphous aluminosilica samples, indicating that the textural surface parameters $\left(\mathrm{S}_{\mathrm{BET}}\right.$, as well as pore volumes and orders) and pore organizations significantly affected adsorption functionality in terms of diffusivity and binding coverage surfaces of pollutants onto the adsorbent monoliths (Figure 6). In addition, the mesocylinder dimensions (2D hexagonal or 3D cubic) of aluminosilica adsorbents play significant effects on the overall adsorption efficiency with the reuse cycles of adsorption assays of the organic molecules The reusability of the hexagonal and cubic adsorbent monoliths is of particular interest in developing recyclable adsorption systems (Figure 7). After a complete adsorption process, the solid monoliths were collected and repeatedly washed with an acidic aqueous solution $\left[\mathrm{HCl}=1 \times 10^{-3} \mathrm{M}\right]$ and then dried at $200{ }^{\circ} \mathrm{C}$ for $12 \mathrm{~h}$ under air to remove the remaining molecular adsorbates. Reused hexagonal and cubic adsorbents are still effective for the adsorption of organic adsorbates after six recycles (Figure 7). However, no significant changes in the adsorbent affinity toward the removal of organic pollutants, for example with p-Cl-Ar- $\mathrm{NH}_{2}$, from the aqueous solution were observed after several cycles.

To investigate the features of the adsorption process and the interior diffusion into mesocylinder pore cavities of monoliths, we carried out the thermodynamic studies of organic adsorption into hexagonal adsorbents, for example, at different temperatures at 35 - 50 ${ }^{\circ} \mathrm{C}$ range (Table 2). The thermodynamic equilibrium constant, $K_{c}$ of the adsorbed molecules deduced from the following equation [37]:

$$
\mathrm{K}_{\mathrm{c}}=\mathrm{q}_{\mathrm{f}} /\left(1-\mathrm{q}_{\mathrm{f}}\right)
$$

where $q_{f}$ is the ratio of the amount of molecule adsorbed at a time $\left(q_{t}\right)$ to that adsorbed at infinity $\left(q_{\infty}\right)$, (i.e. $\left.q_{f}=q_{t} / q_{\infty}\right)$. From the value of $K_{\mathrm{c}}$, the Gibbs free energy change, $\Delta G$, can be derived. The plot of $\ln K_{\mathrm{c}}$ vs. $1=T$ (Figure 8 ) gives the numerical values of $\Delta H$ of the adsorption of organic pollutants, $\Delta G$ and $\Delta S$, using the following relations (Table 2) $[38]:$

$$
\Delta \mathrm{G}=-\mathrm{RT} \ln \mathrm{K}_{\mathrm{c}}
$$

$$
\ln \mathrm{K}_{\mathrm{c}}=(-\Delta \mathrm{H} / \mathrm{RT})+\Delta \mathrm{S} / \mathrm{R}
$$

where $\Delta H, \Delta S, \Delta G$, and $T$ are the changes in enthalpy, in entropy, and in Gibbs free energy, and the temperature in Kelvin, respectively. $\mathrm{R}$ is the gas constant. The plot of $\ln K_{\mathrm{c}}$ vs. $1 / T$ (Figure 8 ) gives the numerical values of $\Delta H$ of the adsorption of organic pollutants. $\Delta G$ and $\Delta S$ are calculated and presented in Table 2 . The thermodynamic equilibrium constant, $K_{c}$ increased with temperature for all adsorption assays, whereas the absolute value of $\Delta G$ increases with decreasing temperature. This result indicates that adsorption is spontaneous and more favourable at high temperature, which confirmed an endothermic adsorption process. In addition, the $\Delta \mathrm{S}$ value decreases in this sequence: $\mathrm{Ar}-\mathrm{NH}_{2}>p-\mathrm{Cl}-\mathrm{Ar}-\mathrm{NH}_{2}>o-\mathrm{NH}_{2}-\mathrm{Ar}-\mathrm{OH}>p-\mathrm{NO}_{2}-$ Ar- $\mathrm{NH}_{2}$, contributing to a greater value of $\mathrm{K}_{c}$ and greater stability of thermodynamic adsorption. This thermodynamic finding indicated that these adsorbent monoliths with multidirectional macro-and mesocylinder pore cavities show promise for the spontaneous removal and decontamination of organic containments from aqueous water.

\section{Conclusion}

Hexagonal and cubic aluminosilica adsorbents with high aluminium contents $\geq 1$ and mesocyliner pore cavities were fabricated using a simple, reproducible and direct synthesis. The coordination and location of aluminium sites in the frameworks play a key role in the generation of the surface acidity of aluminosilica monoliths, which enhanced the adsorption capacity of the organic pollutants. Adsorption theoretical models were developed to explain the adsorbed molecules into the microscopic geometry and the pore orientation of aluminosilica monoliths. In addition, the electronic structures were also calculated to give insight about the surface properties during the adsorption process. Results indicated that the adsorption uptake of organic pollutants onto both hexagonal and cubic the adsorbents was increased in the order of $p-\mathrm{NO}_{2}-\mathrm{Ar}-\mathrm{NH}_{2}<o-\mathrm{NH}_{2}-\mathrm{Ar}-\mathrm{OH}<p-\mathrm{Cl}-\mathrm{Ar}-$ $\mathrm{NH}_{2}<\mathrm{Ar}-\mathrm{NH}_{2}$. The adsorption uptake also depends on the amount of surface functional groups. Results also revealed that the hexagonal and cubic adsorbents are still effective for the adsorption of organic contaminants after six recycles. The thermodynamic studies, in general, indicated that these adsorbent monoliths with multidirectional macroand mesocylinder pore cavities show promise for the spontaneous removal and decontamination of organic containments from aqueous

\begin{tabular}{|c|c|c|c|c|c|}
\hline \multirow[b]{2}{*}{ Adsorbate } & \multirow[b]{2}{*}{$\begin{array}{l}\mathrm{T} \\
{ }^{\circ} \mathrm{C}\end{array}$} & \multirow[b]{2}{*}{$\mathrm{K}_{\mathrm{c}}$} & \multicolumn{3}{|c|}{ Thermodynamic parameters } \\
\hline & & & $\begin{array}{l}\Delta \mathbf{G} \\
\mathbf{k J} \mathrm{mol}^{-1}\end{array}$ & $\begin{array}{l}\Delta \mathrm{H} \\
\mathrm{kJJmol}^{-1}\end{array}$ & $\begin{array}{l}\Delta S \\
\mathrm{JK}^{-1} \mathrm{~mol}^{-1}\end{array}$ \\
\hline Ar- $\mathrm{NH}_{2}$ & $\begin{array}{l}30 \\
35 \\
40 \\
45\end{array}$ & $\begin{array}{l}3.7 \\
4.1 \\
4.6 \\
4.9\end{array}$ & $\begin{array}{l}-3.30 \\
-3.66 \\
-3.98 \\
-4.25\end{array}$ & 22.0 & 82.0 \\
\hline$p$-Cl-Ar-NH${ }_{2}$ & $\begin{array}{l}30 \\
35 \\
40 \\
45\end{array}$ & $\begin{array}{l}2.9 \\
3.4 \\
4.0 \\
4.5\end{array}$ & $\begin{array}{l}-2.73 \\
-3.19 \\
-3.62 \\
-3.98\end{array}$ & 18.0 & 63.9 \\
\hline $\mathrm{O}-\mathrm{NH}_{2}-\mathrm{Ar}-\mathrm{OH}$ & $\begin{array}{l}30 \\
35 \\
40 \\
45\end{array}$ & $\begin{array}{l}2.4 \\
2.9 \\
3.1 \\
3.4\end{array}$ & $\begin{array}{l}-2.25 \\
-2.74 \\
-3.03 \\
-3.29\end{array}$ & 17.4 & 63.5 \\
\hline$p-\mathrm{NO}_{2}-\mathrm{Ar}-\mathrm{NH}_{2}$ & $\begin{array}{l}30 \\
35 \\
40 \\
45\end{array}$ & $\begin{array}{l}2.3 \\
2.6 \\
2.9 \\
3.1\end{array}$ & $\begin{array}{l}-2.14 \\
-2.51 \\
-2.77 \\
-3.02\end{array}$ & 15.4 & 58.0 \\
\hline
\end{tabular}
water. Such integration of nano-adsorbents is the key to the further development of the environmental cleanup of toxic organic molecules.

Table 2: Illustration of the kinetic and thermodynamic parameters of the adsorption of $\left[1.6 \times 10^{-3} \mathrm{M}\right]$ organic pollutants into hexagonal aluminosilica monolith adsorbents $[10 \mathrm{~g} / \mathrm{L}]$ with a Si/Al ratio of 1.0 
Citation: EL-Safty SA, Khairy M, Ismael M (2012) Nanoadsorbent of Organic Compounds Based on Two- and Three-Dimensional Mesocylinder Monoliths. J Environ Anal Toxicol 2:147. doi:10.4172/2161-0525.1000147

\section{References}

1. Faust SD, Aly OM (1987) Adsorption process for water treatment. Butterworth publishers, London, UK.

2. El-Safty SA, Shahat A, Warkocki W, Ohnuma M (2011) Building-Block-Based Mosaic Cage Silica Nanotubes for Molecular Transport and Separation. Small 7: 62-65.

3. Ram NM, Christman RF, Cantor KP (1990) Significant and treatment of volatile organic compounds in water supplies. Lewis publishers, USA.

4. Cave DA, Foster PM (1990) Modulation of m-dinitrobenzene and m-nitrosonitrobenzene toxicity in rat sertoli-germ cell cocultures. Fundam Appl Toxicol 14: 199-207.

5. El-Safty SA, Ahmed Shahat A, Awual MR (2011) Efficient adsorbents of nanoporous aluminosilicate monoliths for organic dyes from aqueous solution. J Colloid Interface Sci 359: 9-18.

6. Kornaros M, Lyberatos G (2006) Biological treatment of waste waters from a dye manufacturing company using a trickling filter. J Hazard Mater 36: 95-102.

7. Buonomenna MG, Gordano A, Golemme G, Drioli E (2009) Preparation, characterization and use of PEEKWC nanofiltration membranes for removal of Azur B dye from aqueous media. React Funct Polym 69: 259-263.

8. El-Safty SA, Kiyozumi Y, Hanaoka T, Mizukami F (2008) Nanosized NiO particles wrapped into uniformly mesocaged silica structures as efficient catalysts. Appl Catal A 337 (1): 121-129.

9. Payne GF, Shuler ML (1988) Selective adsorption of plant products. Biotechno Bioeng 31: 922-928.

10. Uribe A, Bishop PL, Pinto NG (2002) The influence of $\mathrm{pH}$ and temperature changes on the adsorption behavior of organophilic clays used in the stabilization/solidification of hazardous wastes. Environ Eng Sci 1: 123-133.

11. Nasuto R, Derylo A (1980) Effect of temperature on adsorption of aniline from benzene solutions on silica-gel. Pol J Chem 54: 1089.

12. Titus E, Kalkar AK, Gaikar VG (2002) Adsorption of anilines and cresols on $\mathrm{NaX}$ and different cation exchanged zeolites (equilibrium, kinetic, and IR investigations). Sep Sci Technol 37: 105-125.

13. Essington ME (1994) Adsorption of aniline and toluidines on montmorillonite. Soil Science 158: 181.

14. Gürten AA, Ucan S, Özler MA, Ayar A (2005) Removal of aniline from aqueous solution by PVC-CDAE ligand-exchanger. J Hazard Mater 120: 81-87.

15. Jianguo C, Aimin L, Hongyan S, Zhenghao F, Chao L, et al. (2005) Adsorption characteristics of aniline and 4-methylaniline onto bifunctional polymeric adsorbent modified by sulfonic groups. J Hazard Mater 124: 173-180.

16. Duman O, Ayranic E (2005) Structural and ionization effects on the adsorption behaviors of some anilinic compounds from aqueous solution onto high-area carbon-cloth. J Hazard Mater 120: 173-181.

17. Villacanas F, Pereira MFR, Orfao JM, Figueiredo JL (2006) Adsorption of simple aromatic compounds on activated carbons. J Colloid Interface Sci 293 $128-136$

18. Ardizzone S, Hoiland H, Lagioni C, Sivieri E (1998) Pyridine and aniline adsorption from an apolar solvent: the role of the solid adsorbent. J Electroanal Chem 447: 17-23.

19. Potter OG, Hilder EF (2008) Porous polymer monoliths for extraction: Diverse applications and platforms. J Sep Sci 31:1881-1906.

20. El-Safty S A (2009) Functionalized hexagonal mesoporous silica monoliths with hydrophobic azo-chromophore for enhanced Co(II) ion monitoring. Adsorption 15: 227-239.

21. Wei F, Yang JY, Gao L, Gu FN, Zhu JH (2009) Capturing nitrosamines in tobacco-extract solution by hydrophobic mesoporous silica. J Hazard Mater 172: $1482-1490$.

22. El-Safty SA, Khairy M, Ismael M, (2012) Visual detection and revisable supermicrostructure sensor systems of $\mathrm{Cu}(\mathrm{II})$ analytes. Sens Actuators B: Chemical 166-167: 253-263.

23. Balaji T, El-Safty SA, Matsunaga H, Hanaoka T, Mizukami F (2006) Optical Sensors Based on Nanostructured Cage Materials for the Detection of Toxic Metal lons. Angew Chem Int Ed Engl 45: 7202-7208.
24. El-Safty SA, Mekawy MA, Yamaguchi A, Shahat A, Ogawa K, et al. (2010) Organic-inorganic mesoporous silica nanostrands for ultrafine filtration of spherical nanoparticles. Chem Commun 46: 3917-3919.

25. El-Safty SA (2011) Designs for size-exclusion separation of macromolecules by densely-engineered mesofilters. TrAC Trends Anal Chem 30: 447-458.

26. Wang Y, Lang N, Tuel A (2006) Nature and acidity of aluminium species in AIMCM-41 with a high aluminium content $(\mathrm{Si} / \mathrm{Al}=1.25)$. Microporous Mesoporous Mater 93: 46-54.

27. Climent M J, Corma A, Iborra S, Navarro MC, Primo J (1996) Use of Mesoporous MCM-41 Aluminosilicates as Catalysts in the Production of Fine Chemicals: Preparation of Dimethylacetals. J Catal 161: 783-789.

28. Kresge CT, Leonowicz ME, Roth WJ, Vartuli JC, Beck JS (1992) Ordered mesoporous molecular sieves synthesized by a liquid-crystal template mechanism. Nature 359: 710-712.

29. Beck JS, Vartuli JC, Roth WJ, Leonowicz ME, Kresge CT, et al. (1992) A new family of mesoporous molecular sieves prepared with liquid crystal templates. J. Am. Chem. Soc 114: 10834-10843.

30. El-Safty SA, Kiyozumi Y, Hanaoka T, Mizukami F (2008) Controlled design of ordered and disordered pore architectures, geometries, and dimensions of HOM-Type mesostructured monoliths and their hydrothermal stabilities. J Phys Chem C 112: 5476-5489.

31. El-Safty SA, Prabhakaran D, Kiyozumi Y, Mizukami F (2008) Nanoscale membrane strips for benign sensing of $\mathrm{Hg}$ ii ions: a route to commercial waste treatments. Adv Funct Mater 18: 1739-1750

32. El-Safty SA (2008) Review on the key controls of designer copolymer-silica mesophase monoliths (HOM-type) with large particle morphology ordered geometry and uniform pore dimension. J Porous Mater 15: 369-387.

33. El-Safty SA, Shahat A, Ogawa K, Hanaoka T (2011) Highly ordered thermally/ hydrothermally stable cubic la3d aluminosilica monoliths with low silica in frameworks. Microporous Mesoporous Mater 138: 51-62.

34. Timofeeva MN, Panchenko VN, Gil A, Chesalov Y, Sorokina TP, et al. (2010) Synthesis of propylene glycol methyl ether from methanol and propylene oxide over alumina-pillared clays. Appl Catal B 102: 433-440.

35. Gaussian 09, Revision B, Frisch MJ, Trucks GW, Schlegel HB, et al.(2004) Gaussian 03 Rev.E.01 \& Rev.D.01, Gaussian, Inc., Wallingford, CT, USA

36. El-Safty SA, Shenashen MA, Khairy M, Ismeal M (2012) Encapsulation of proteins into tunable and giant mesocage alumina. Chem Commun 48: 67086710.

37. El-Safty SA, Shenashen MA, Khairy M, Ismeal M (2012) Mesocylindrica Aluminosilica Monolith Biocaptors for Size-Selective Macromolecule Cargos. Adv Funct Mater.

38. El-Safty SA, Khairy M, Ismeal M, Kawarada H, (2012) Multidirectional porous $\mathrm{NiO}$ nanoplatelet-like mosaics as catalysts for green chemical transformations. Appl Catal B Envirom 123-124: 162-173. 